\title{
Comparison of the results of transcatheter aortic valve implantation in patients with bicuspid and tricuspid aortic valve
}

\author{
Piotr A. Chodór ${ }^{1}$, Krzysztof Wilczek ${ }^{2}$, Karolina Chodór-Rozwadowska ${ }^{3}$, Roman Przybylski ${ }^{4}$, Jan Głowacki ${ }^{5}$, \\ Tomasz Niklewski ${ }^{6}$, Łukasz Włoch ${ }^{1}$, Mariusz Gąsior ${ }^{2}$, Marian Zembala $^{6}$, Zbigniew Kalarus ${ }^{1}$
}

\begin{abstract}
${ }^{1}$ Department of Cardiology, Congenital Heart Diseases and Electrotherapy, Medical University of Silesia, Silesian Center for Heart Diseases, Zabrze, Poland

${ }^{2} 3^{\text {rd }}$ Department of Cardiology, Medical University of Silesia, Silesian Center for Heart Diseases, Zabrze, Poland

${ }^{3}$ Doctoral School, Department of Cardiology, Congenital Heart Diseases and Electrotherapy, Medical University of Silesia, Silesian Center for Heart Disease, Zabrze, Poland

${ }^{4}$ Department of Heart Diseases, Clinic of Cardiac Transplantation and Mechanical Circulatory Support, Wroclaw Medical University, Wroclaw, Poland

${ }^{5}$ Department of Radiology, Medical University of Silesia, Diagnostic Department, Silesian Center for Heart Diseases, Zabrze, Poland ${ }^{6}$ Department of Cardiac Surgery and Transplantology, Medical University of Silesia, Silesian Center for Heart Diseases, Zabrze, Poland
\end{abstract}

\begin{abstract}
A bstract
Introduction: Indications for transcatheter aortic valve implantation (TAVI) are constantly expanding, including younger patients. Bicuspid aortic valves (BAV) often occur in this group. In order to achieve optimal treatment results in younger patients, it is necessary to develop an effective method for selecting the size of implanted valves.

Aim: To compare the results of TAVI with use of a self-expanding prosthesis in patients with a BAV and a tricuspid aortic valve (TAV) with valve selection based on annular sizing.

Material and methods: The diagnosis of BAV and TAV and measurements (annular sizing) were based on multi-slice computed tomography scans. Eighty-three patients received a self-expanding CoreValve or Evolut R prosthesis. In group I (BAV) there were $21(25.3 \%)$ patients and in group II (TAV) there were 62 (74.7\%) patients.

Results: The groups did not differ in terms of baseline clinical characteristics. Device success was achieved in $16(76.2 \%)$ and $55(88.7 \%)(p=N S)$ in group I and II respectively. Composite endpoints: early safety occurred in $5(23.8 \%)$ and $11(17.7 \%)$ patients $(p=N S)$ in group I and II respectively; clinical efficacy occurred in $10(47.6 \%)$ and $28(45.2 \%)$ patients $(p=$ NS) in group I and II respectively. 30-day mortality was $4.8 \%$ vs $9.7 \%, 1$-year mortality was $28.6 \%$ vs $17.7 \%$ ( $p=$ NS) in group I and II respectively.

Conclusions: TAVI in patients with severe aortic stenosis and BAV is as effective as in patients with TAV using self-expanding prostheses if the valve selection is based on annular sizing.
\end{abstract}

Key words: transcatheter aortic valve implantation, bicuspid aortic valve, multi-slice computed tomography.

S u m m a ry

Expansion of transcatheter aortic valve implantation (TAVI) towards the younger population will result in higher frequency of the procedures in patients having bicuspid aortic valve (BAV). Implantation results in patients with BAV are ambiguous. Different diagnostic methods are used for diagnosis of BAV, various prostheses are being evaluated in this subpopulation and different valve size selection methods are applied. Our study presents the results of TAVI procedures in patients with BAV and TAV, which are diagnosed based on a uniform method - multi-slice computed tomography scans. Only self-expanding valves were used in the study and a uniform valve selection method based on valve annulus measurements was used. Our results show that the use of self-expanding valves in the size selection based on annulus measurements is equally effective in patients with BAV and TAV.

\section{Corresponding author:}

Piotr A. Chodór MD, Department of Cardiology, Congenital Heart Diseases and Electrotherapy, Medical University of Silesia,

Silesian Center for Heart Diseases, Zabrze, Poland, phone: +48 3227353 56, e-mail: chodor_piotr@go2.pl

Received: 8.10.2020, accepted: 13.02.2021. 


\section{Introduction}

A bicuspid aortic valve (BAV) occurs in $0.5-2 \%$ of the population [1-3]. This defect predisposes to aortic stenosis, aortic regurgitation, ascending aorta dilatation, and infective endocarditis [3-6]. The incidence of BAV among patients with aortic stenosis depends on patient age. In younger age groups, the incidence is higher in patients qualified for aortic valve surgery and is $59.8 \%$ in patients aged $61-70$, while it is $25.7 \%$ in older patients (e.g., aged 81-90) [7]. According to the transcatheter aortic valve implantation (TAVI) registries, BAV affects $6-8 \%$ of patients $[8,9]$. Currently, the vast majority of patients referred for TAVI are high-risk surgical patients. Intermediate-risk surgical patients are also referred for TAVI in accordance with the 2017 European Society of Cardiology guidelines [10]. In the coming years, further extension of indications to younger patients should be expected, among whom the BAV incidence will increase. The results of TAVI procedures in BAV patients are ambiguous. Some studies indicate higher early mortality and lower procedural efficacy, while others indicate increased paravalvular leaks and a higher permanent pacemaker implantation rate $[1,3,11,12]$. Factors that increase difficulties in interpreting results include the method of BAV diagnosis (echocardiography or multi-slice computed tomography (MSCT)), the method of valve selection, as well as the use of different generations of valves and valves with different implantation mechanisms [1, 2, 4].

\section{Aim}

The aim of this study is to compare the results of TAVI with the use of a self-expanding prosthesis CoreValve/ Evolut R in BAV and tricuspid aortic valve (TAV) patients. The valve size was selected based on measurements of the aortic annulus using MSCT scans.

\section{Material and methods}

The TAVI Zabrze Registry is a study collecting data on patients with severe aortic stenosis who were referred for TAVI procedures. The aim of the registry is to monitor treatment outcomes of patients with aortic stenosis in terms of safety, therapeutic efficacy, and cost-effectiveness.

Between November 26, 2008, and December 31, 2016, 161 patients with severe symptomatic aortic stenosis were qualified for TAVI procedures by our Heart Team. The analysis included 83 patients in whom the valve was selected based on the aortic annulus measurements using MSCT scans and in whom CoreValve and Evolut R self-expanding valves were implanted. Valve morphology was determined using MSCT scans. The prostheses were selected by measuring the aortic annulus's diameter applying the following formula: aortic annulus perimeter in $\mathrm{MSCT} / \pi$. The valves were selected based on Medtronic's recommendations. The first 46 (28.6\%) patients were found ineligible for anal- ysis because the prostheses were selected based on transthoracic and transesophageal echocardiography and the results of the aortic annulus measurements using MSCT scans in one sagittal plane only. The population of patients was defined as a group of patients on the learning curve. The study excluded 13 (8.1\%) patients who received the Edwards SAPIEN valves and 3 (1.9\%) patients who underwent a valve-in-valve procedure. The data on 12 (7.5\%) patients were excluded from the analysis due to the MSCT scans' poor quality. Another 4 (2.5\%) BAV patients were excluded from the study because the valve was implanted deliberately based on the measurements above the aortic annulus, at the height of valve leaflets. Figure 1 shows how patients were qualified for the analysis.

Before the procedure, the patients gave their informed consent to the proposed treatment. The patients were divided into groups based on valve morphology: group I consisted of 21 (24.7\%) BAV patients, and group II consisted of 62 (74.7\%) TAV patients.

\section{MSCT examination and measurements}

The MSCT examination was performed according to the previously described protocol [13]. Measurements of the aortic annulus, roots, and aorta were performed using OsiriX Pro software (by Pixmeo SARL, Switzerland). Aortic annulus measurements comprised: minimum size, maximum size, perimeter, and area of the annulus. The aortic annulus diameter obtained from aortic annulus perimeter measurements was used to select the prosthesis.

161 patients treated in 2008-2016

\begin{tabular}{|l|l|}
$-46(28.6 \%)$ of the first patients, in whom \\
valves were selected based on TTE/TEE and \\
single-plane MSCT (learning curve) \\
$-3(1.9 \%)$ TAVI procedures in which the valve \\
was implanted into a degenerated \\
biological aortic valve (valve-in-valve) \\
$-13(8.1 \%)$ Edwards SAPIEN valves \\
$-12(7.5 \%)$ cases, in which valve morphology \\
could not be determined clearly due to \\
MSCT quality \\
$-4(2.5 \%)$ patients, in whom the valve that \\
was not selected based on the measure- \\
ment of the aortic annulus \\
\end{tabular}

$83(51.2 \%)$ patients, in whom the CoreValve or Evolut $R$ valve selec tion was based on the measurement of the aortic annulus using MSCT scans. BAV and TAV diagnosis was based on MSCT scans exclusively

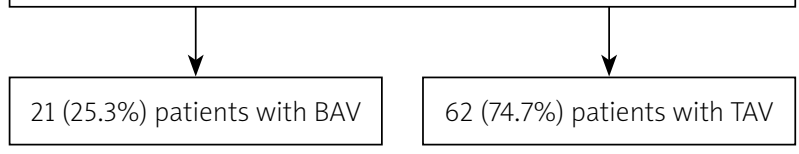

Figure 1. Flow chard

BAV - bicuspid aortic valve, MSCT - multi-slice computed tomography, TAV - tricuspid aortic valve, TAVI - transcatheter aortic valve implantation, TEE - transesophageal echocardiography, TTE - transthoracic echocardiography. 
Oversizing was defined as the perimeter's ratio at the base of the implanted valve to the perimeter of the native valve annulus according to the following formula: valve perimeter/annulus perimeter $\times 100 \%-100$. The diagnosis of BAV was made based on the MSCT examination, according to the Sievers and Schmidtke classification [14]. Type 0 was diagnosed when two fully developed cusps were present with no raphe and one commissure (true BAV); type 1 when one fully developed cusp was present with two smaller cusps joined with one raphe; and type 2 when two raphae were present (Figures 2 A, B). Functional BAV was diagnosed when three more or less symmetrical cusps were present with no raphe, but their secondary fusion was present due to degeneration of the valve (Figures 2 C, D). Each raphe or cusp fusion was analyzed in three perpendicular planes. The analysis consisted of shifting the intersection plane parallel to the annulus from the left ventricular outflow tract towards
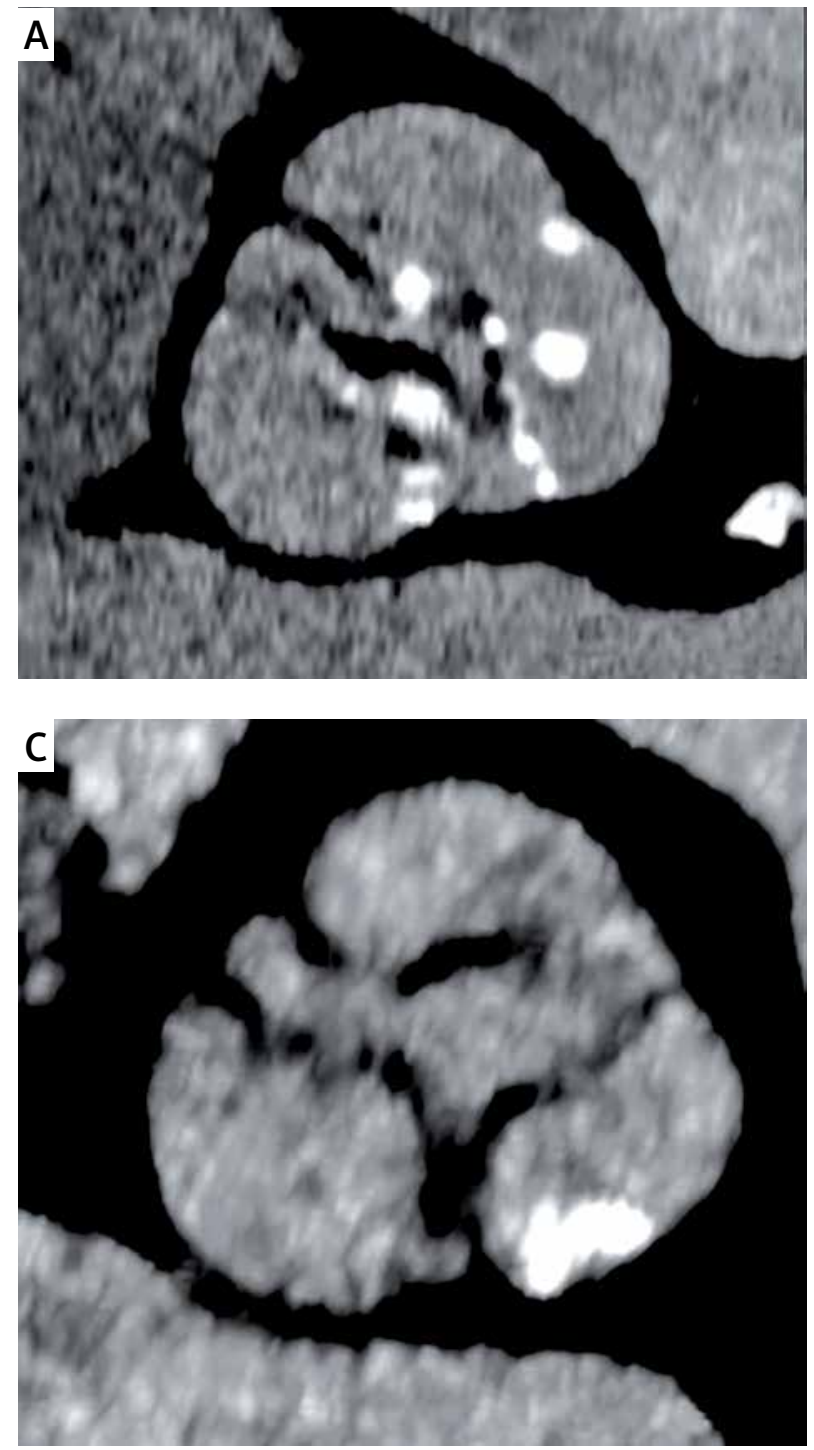

Figure 2. A - Bicuspid aortic valve with raphe type $1 \mathrm{~L} / \mathrm{R}$. B - Raphe with calcification in patient with bicuspid aortic valve type $1 \mathrm{~L} / \mathrm{R}$. C, D - Functional bicuspid aortic valve with fusion of the valve leaflets L/N the aorta to the top of leaflets and shifting the plane perpendicular to the raphe/the fusion from the center of the aortic valve to the circumference. In 3 cases, the BAV analysis was supported by MSCT image sequences at different R-R intervals: $10 \%, 20 \%, 30 \% . . .100 \%$. For this purpose, a Somatom Definition Flash (Siemens Forcheim Germany) was used.

TAVI procedures were performed in a catheterization laboratory or a hybrid operating room. Seventy-one (85.5\%) CoreValves and eleven (13.3\%) Evolut R valves (Medtronic, Minneapolis, MN, USA), in sizes 26, 29, 31, were implanted. All procedures were performed routinely, as described elsewhere $[13,15,16]$.

\section{Angiographic assessment}

After valve implantation, the paravalvular leak was assessed angiographically based on the Sellers classifi-
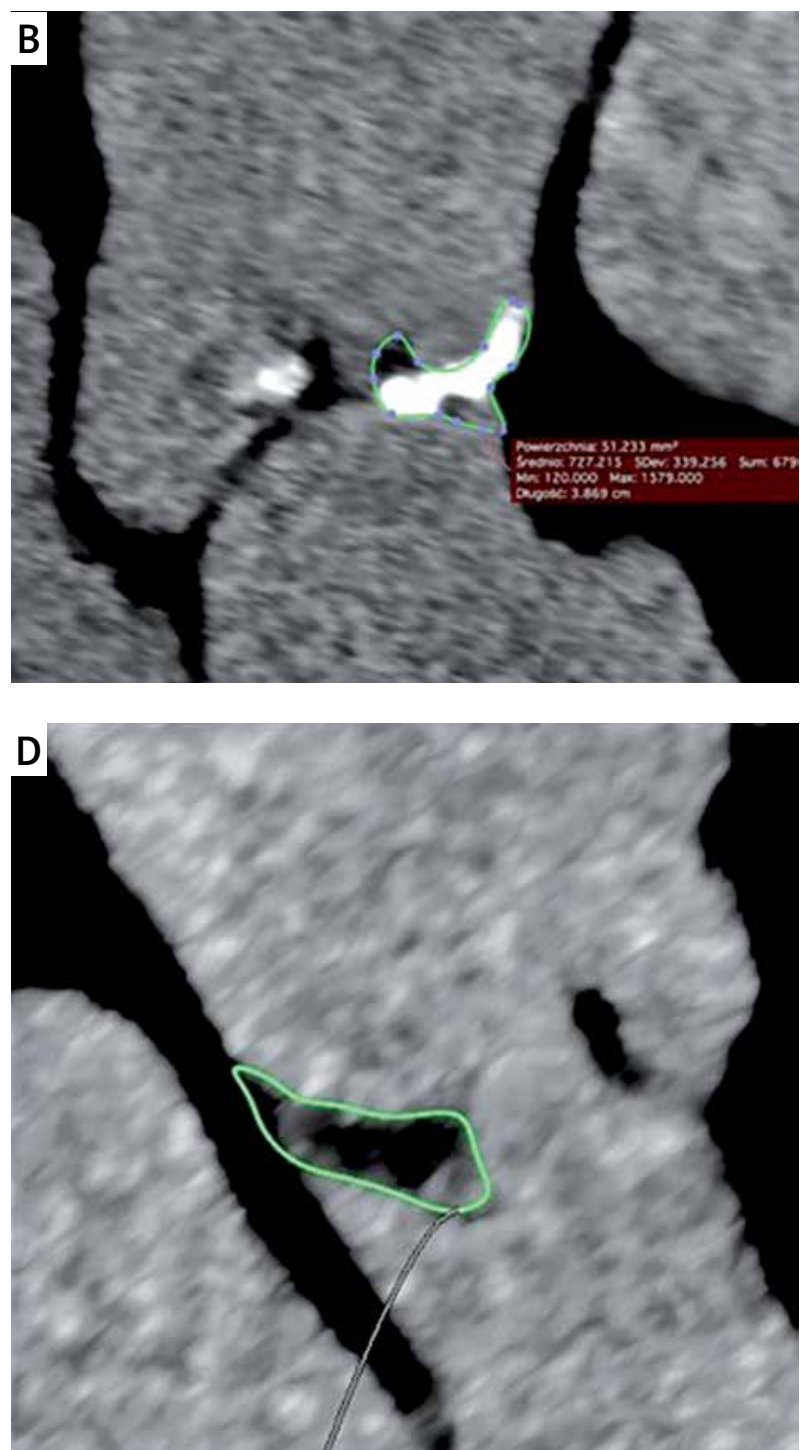
cation of aortic regurgitation [17]. A contrast agent (15$20 \mathrm{ml}$ ) was administered at $10 \mathrm{ml} / \mathrm{s} 450$ PSI. The evaluation was carried out independently by three experienced interventional cardiologists. A common position was agreed upon in case of discrepancies. Seventy-seven aortographies were analyzed after valve implantation. In $6(7.23 \%)$ patients, aortography was not performed, mainly due to renal failure.

Composite endpoints were adopted according to the criteria of the Valve Academic Research Consortium (VARC 2), i.e., device success, early safety (at 30 days), and clinical efficacy (1-year evaluation) [18].

The patients were evaluated during the hospital stay, 30 days, and 6-12 months after the procedure at the cardiology outpatient clinic.

\section{Statistical analysis}

The results obtained are presented as a standard deviation and mean value. The Kolmogorov-Smirnov test was used to evaluate the compatibility between distributions and a normal distribution. Student's $t$-test was used for dependent and independent variables when the pair's distribution was similar to the normal distribution. Yates's $\chi^{2}$ test and Fisher's exact test were used for assessing differences among categorical parameters. The Kaplan-Meier analysis enabled us to determine survival. The log-rank test was used to compare survival curves. The value of $p<0.05$ was considered statistically significant. All calculations were done using Statistica 10 software (TIBCO Software Inc., Palo Alto, California).

\section{Results}

Baseline characteristics of patients are shown in Table I. Patients did not differ significantly in terms of basic clinical, echocardiographic, and MSCT parameters.

According to the Sievers and Schmidtke classification, none of the patients had type $0,13(61.9 \%)$ had type 1 , 3 (14.3\%) had type 2 , and 5 (23.8\%) had functional BAV.

The results of TAVI treatment are presented in Table II. Second valve implantation was necessary in 2 patients of the BAV group (due to valve embolization to the ascending aorta) and 2 patients of the TAV group (in 1 patient due to valve embolization and the second one due to very low implantation associated with a severe paravalvular leak).

Valves were not implanted in 2 patients. In 1 BAV patient, the venous graft was damaged during transaortic access as part of the sternotomy, and symptoms of myocardial infarction occurred. Coronary artery bypass grafting was performed, and TAVI was postponed. The patient died on postoperative day two. During subclavian access in 1 TAV patient, after valvuloplasty, symptoms of ischemia appeared, leading to cardiogenic shock with cardiac arrest. The patient died despite resuscitation before valve implantation.
After TAVI, comparable results were obtained in both groups. The groups did not differ in terms of effective orifice area (EOA), mean aortic valve gradient, or left ventricle ejection fraction. In the echocardiographic assessment, 3 (14.28\%) BAV patients had a moderate paravalvular leak (patients with CoreValve). Six (9.67\%) TAV patients had a moderate paravalvular leak (patients with CoreValve). In the angiographic assessment of paravalvular leak, according to Sellers, no significant differences between those two groups were found. Grade 3 paravalvular leak in the angiographic assessment occurred only in 1 (4.7\%) BAV patient (CoreValve prosthesis). There was no grade 3 paravalvular leak in any TAV patient (Table II).

During the hospital stay, 4 (19.05\%) BAV patients required permanent pacemaker implantation. In the TAV group, $15(24.2 \%)$ patients ( $p=N S)$ needed permanent pacemaker implantation (Table II).

Patients from the two groups did not differ significantly in terms of device success, early safety, clinical efficacy (1-year evaluation according to VARC 2 criteria) or individual components of these composite endpoints. The results are shown in Table III. Kaplan-Meier survival curves demonstrated similar survival probability at longterm observation (Figure 3).

\section{Discussion}

The results of TAVI treatment of BAV patients are presented in comparison with TAV patients. It is a single-center study, using one type of transcatheter prosthesis and a homogeneous procedure for valve selection (annular sizing). A uniform way of BAV diagnosis - based on MSCT scans - was also applied.

The classification of BAV used in the study refers to the full spectrum of morphologies presented in the material of BAV by taking into account the Sievers classification and the presence of functional BAV. The Sievers classification is a surgical/anatomopathological classification, and the recently introduced Jilaihawi classification is based on MSCT studies. We did not use Jilaihawi's classification because it does not take into account the valves with two raphae, which are defined by Sievers as type 2 . In our material, there were three such patients. In turn, in Jilaihawi's classification, there is a three-commissural type, which, according to this classification, corresponds to the concept of an acquired, functional BAV [19]. This type of BAV does not fit into the Sievers classification. Our material included 5 patients with functional BAV, which concerns valves with three symmetrical leaflets, but two leaflets are fused at the commissures (Figures 2 C, D). In the literature, there is a concept of a functional BAV in which the adjacent leaflets are fused but are not underdeveloped $[19,20]$. The morphologies of BAV differ very much on CT examination, and not all correspond to the classical Sievers classification. The classification we use is not perfect; however, it reflects the different morphol- 
Table I. Baseline characteristics

\begin{tabular}{|c|c|c|c|c|}
\hline Parameter & All patients $(n=83)$ & BAV $(n=21)$ & $\operatorname{TAV}(n=62)$ & $P$-value \\
\hline \multicolumn{5}{|l|}{ Clinical characteristic: } \\
\hline Age [years] & $77.45 \pm 8.33$ & $75.76 \pm 7.96$ & $78.03 \pm 8.44$ & NS \\
\hline Male & $51(61.45 \%)$ & $14(66.67 \%)$ & $37(59.67 \%)$ & NS \\
\hline $\mathrm{BMI}$ & $17.79 \pm 5.16$ & $27.06 \pm 2.29$ & $28.04 \pm 5.81$ & NS \\
\hline $\mathrm{BSA}\left[\mathrm{m}^{2}\right]$ & $1.85 \pm 0.19$ & $1.85 \pm 0.16$ & $1.85 \pm 0.21$ & NS \\
\hline \multicolumn{5}{|l|}{ NYHA: } \\
\hline I & $5(6.02 \%)$ & $2(9.52 \%)$ & $3(4.84 \%)$ & NS \\
\hline 11 & $30(36.1 \%)$ & $8(38.09 \%)$ & $22(35.48 \%)$ & NS \\
\hline III & $37(44.58 \%)$ & $10(47.62 \%)$ & $27(43.55 \%)$ & NS \\
\hline IV & $11(13.25 \%)$ & $1(4.76 \%)$ & $10(16.13 \%)$ & NS \\
\hline Hypertension & $68(81.93 \%)$ & $16(76.19 \%)$ & $52(83.87 \%)$ & NS \\
\hline Type 2 diabetes & $36(43.34 \%)$ & $10(47.62 \%)$ & $26(41.93 \%)$ & NS \\
\hline Smoking & $31(37.35 \%)$ & $9(42.86 \%)$ & $22(35.48 \%)$ & NS \\
\hline COPD & $20(24.09 \%)$ & $4(19.05 \%)$ & $16(25.8 \%)$ & NS \\
\hline Extracardiac arteriopathy & $32(38.55 \%)$ & $10(47.62 \%)$ & $22(35.48 \%)$ & NS \\
\hline Stroke/TIA & $10(12.05 \%)$ & $5(23.81 \%)$ & $5(8.06 \%)$ & 0.0553 \\
\hline Previous MI & $31(37.35 \%)$ & $9(42.86 \%)$ & $22(35.48 \%)$ & NS \\
\hline Previous CABG & $29(34.93 \%)$ & $9(42.86 \%)$ & $19(30.64 \%)$ & NS \\
\hline Previous PCl & $16(19.27 \%)$ & $3(14.29 \%)$ & $13(20.97 \%)$ & NS \\
\hline Renal impairment & $48(14.46 \%)$ & $11(52.38 \%)$ & $37(59.68 \%)$ & NS \\
\hline Pacemaker implantation & $12(14.46 \%)$ & $3(14.29 \%)$ & $9(14.52 \%)$ & NS \\
\hline DDDR & $5(6.03 \%)$ & $1(4.76 \%)$ & $4(6.45 \%)$ & NS \\
\hline VVIR & $5(6.03 \%)$ & $1(4.76 \%)$ & $4(6.45 \%)$ & NS \\
\hline ICD & $1(1.21 \%)$ & $0(0.0 \%)$ & $1(1.62 \%)$ & NS \\
\hline CRT-D & $1(1.21 \%)$ & $1(4.76 \%)$ & $0(0.0 \%)$ & NS \\
\hline Log EuroSCORE & $21.86 \pm 15.3$ & $21.63 \pm 11.49$ & $22.59 \pm 17.22$ & NS \\
\hline Standard EuroSCORE & $10.44 \pm 2.81$ & $10.47 \pm 2.46$ & $10.43 \pm 2.93$ & NS \\
\hline EuroSCORE II & $8.17 \pm 8.43$ & $7.51 \pm 4.9$ & $8.4 \pm 9.3$ & NS \\
\hline NT -proBNP $[\mathrm{pg} / \mathrm{ml}]$ & $3413.95 \pm 5165.78$ & $2308.4 \pm 2185.42$ & $3764.1 \pm 5770.2$ & NS \\
\hline Previous MI & $31(37.35 \%)$ & $9(42.86 \%)$ & $22(35.48 \%)$ & NS \\
\hline Previous CABG & $29(34.93 \%)$ & $9(42.86 \%)$ & $19(30.64 \%)$ & NS \\
\hline Previous $\mathrm{PCl}$ & $16(19.27 \%)$ & $3(14.29 \%)$ & $13(20.97 \%)$ & NS \\
\hline Renal impairment & $48(14.46 \%)$ & $11(52.38 \%)$ & $37(59.68 \%)$ & NS \\
\hline \multicolumn{5}{|l|}{ Echocardiography: } \\
\hline Annulus diameter [mm] & $23.47 \pm 2.77$ & $23.92 \pm 2.92$ & $23.31 \pm 2.73$ & NS \\
\hline $\mathrm{AVA}\left[\mathrm{cm}^{2}\right]$ & $0.68 \pm 0.24$ & $0.689 \pm 0.19$ & $0.683 \pm 0.25$ & NS \\
\hline Mean AVPG [mm Hg] & $47.84 \pm 17.06$ & $45.6 \pm 18.06$ & $48.57 \pm 16.81$ & NS \\
\hline LVEF [\%] & $46.57 \pm 15.22$ & $46.55 \pm 13.57$ & $46.58 \pm 15.82$ & NS \\
\hline \multicolumn{5}{|c|}{ Multi-slice computed tomography: } \\
\hline Annulus area $\left[\mathrm{cm}^{2}\right]$ & $4.74 \pm 0.94$ & $5.05 \pm 0.93$ & $4.67 \pm 0.94$ & NS \\
\hline Annulus perimeter $[\mathrm{cm}]$ & $7.82 \pm 0.75$ & $8.04 \pm 0.71$ & $7.76 \pm 0.77$ & NS \\
\hline $\begin{array}{l}\text { Diameter derived from } \\
\text { perimeter }[\mathrm{cm}]\end{array}$ & $2.48 \pm 0.24$ & $2.56 \pm 0.23$ & $2.47 \pm 0.25$ & NS \\
\hline Minimum $[\mathrm{cm}]$ & $2.19 \pm 0.25$ & $2.25 \pm 0.22$ & $2.18 \pm 0.26$ & NS \\
\hline Maximum $[\mathrm{cm}]$ & $2.72 \pm 0.29$ & $2.82 \pm 0.29$ & $2.69 \pm 0.29$ & NS \\
\hline Ovality [Max/Min ×100] & $1.24 \pm 0.11$ & $1.26 \pm 0.09$ & $1.24 \pm 0.12$ & NS \\
\hline Oversizing [\%] & $16.21 \pm 6.52$ & $15.47 \pm 5.73$ & $16.45 \pm 6.78$ & NS \\
\hline
\end{tabular}

Data are shown as numbers (percentage) or mean \pm standard deviation. AVA - aortic valve area, AVPG - aortic valve pressure gradient, BAV-bicuspid aortic valve, $B M I$ - body mass index, BSA - body surface area, CABG - coronary artery bypass grafting, COPD - chronic obstructive pulmonary disease, CRT-D - cardiac resynchronization therapy with defibrillator, DDDR - dual chamber rate adaptive pacemaker, ICD - implantable cardioverter-defibrillator, LVEF - left ventricular ejection fraction, MI - myocardial infarction, MSCT - multi-slice computed tomography, NT-pro BNP - N-terminal pro-B-type natriuretic peptide, NYHA - New York Heart Association, $\mathrm{PCl}$ - percutaneous coronary intervention, TIA - transient ischemic attack, TAV-tricuspid aortic valve, VVIR-single chamber rate adaptive pacemaker. 
Table II. Procedural and postprocedural data

\begin{tabular}{|c|c|c|c|c|}
\hline Parameter & All patients $(n=83)$ & $\operatorname{BAV}(n=21)$ & $\operatorname{TAV}(n=62)$ & $P$-value \\
\hline \multicolumn{5}{|l|}{ TAVI procedural data: } \\
\hline \multicolumn{5}{|l|}{ Access: } \\
\hline TF & $59(71.08 \%)$ & $12(57.14 \%)$ & $47(75.81 \%)$ & NS \\
\hline TS & $17(20.48 \%)$ & $6(28.57 \%)$ & $11(17.74 \%)$ & NS \\
\hline TAO & $7(8.43 \%)$ & $3(14.29 \%)$ & $4(6.45 \%)$ & NS \\
\hline Predilatation & $82(98.4 \%)$ & $20(95.2 \%)$ & $62(100 \%)$ & NS \\
\hline Postdilatation & $23(27.7 \%)$ & $7(33.3 \%)$ & $16(25.8 \%)$ & NS \\
\hline Need of second prosthetic valve & $4(4.82 \%)$ & $2(9.52 \%)$ & $2(3.23 \%)$ & NS \\
\hline Tamponade & $2(2.41 \%)$ & $0(0.0 \%)$ & $2(3.23 \%)$ & NS \\
\hline Annulus rupture & $1(1.21 \%)$ & $0(0.0 \%)$ & $1(1.62 \%)$ & NS \\
\hline CoreValve prosthesis: & $70(84.3 \%)$ & $18(85.7 \%)$ & $52(83.9 \%)$ & NS \\
\hline 26 & $15(18.1 \%)$ & $2(9.5 \%)$ & $13(21.0 \%)$ & NS \\
\hline 29 & $29(34.5 \%)$ & $9(42.9 \%)$ & $20(32.3 \%)$ & NS \\
\hline 31 & $26(31.3 \%)$ & $7(33.3 \%)$ & $19(30.6 \%)$ & NS \\
\hline Evolut R prosthesis: & $11(14.5 \%)$ & $2(9.5 \%)$ & $9(14.5 \%)$ & NS \\
\hline 26 & $5(6.0 \%)$ & $1(4.8 \%)$ & $4(6.3 \%)$ & NS \\
\hline 29 & $6(7.2 \%)$ & $1(4.8 \%)$ & $5(8.0 \%)$ & NS \\
\hline \multicolumn{5}{|l|}{ Echocardiographic findings after TAVI: } \\
\hline $\mathrm{EOA}\left[\mathrm{cm}^{2}\right]$ & $1.96 \pm 0.57$ & $2.097 \pm 0.75$ & $1.93 \pm 0.49$ & NS \\
\hline Mean AVG [mm Hg] & $8.63 \pm 6.25$ & $8.16 \pm 3.15$ & $8.81 \pm 7.05$ & NS \\
\hline LVEF [\%] & $49.66 \pm 10.85$ & $47.94 \pm 9.61$ & $50.21 \pm 11.25$ & NS \\
\hline \multicolumn{5}{|l|}{ PVL: } \\
\hline No/trivial & $29(34.94 \%)$ & $8(38.09 \%)$ & $21(33.87 \%)$ & NS \\
\hline Mild & $38(45.78 \%)$ & $9(42.86 \%)$ & $29(46.77 \%)$ & NS \\
\hline Moderate & $9(10.84 \%)$ & $3(14.28 \%)$ & $6(9.67 \%)$ & NS \\
\hline Severe & $0(0.0 \%)$ & $0(0.0 \%)$ & $0(0.0 \%)$ & NS \\
\hline \multicolumn{5}{|l|}{ Angiographic findings after TAVI: } \\
\hline \multicolumn{5}{|l|}{ PVL according to Sellers scale: } \\
\hline 0 & $27(32.53 \%)$ & $8(38.09 \%)$ & $19(30.64 \%)$ & NS \\
\hline 1 & $23(27.71 \%)$ & $7(33.33 \%)$ & $16(25.81 \%)$ & NS \\
\hline 2 & $27(32.53 \%)$ & $4(19.05 \%)$ & $23(37.09 \%)$ & NS \\
\hline 3 & $1(1.21 \%)$ & $1(4.76 \%)$ & $0(0.0 \%)$ & NS \\
\hline Pacemaker implantation after TAVI & $19(22.9 \%)$ & $4(19.05 \%)$ & $15(24.2 \%)$ & NS \\
\hline DDDR & $12(14.46 \%)$ & $4(19.05 \%)$ & $7(11.3 \%)$ & NS \\
\hline VVIR & $3(3.61 \%)$ & $0(0.0 \%)$ & $3(4.84 \%)$ & NS \\
\hline$I C D$ & $1(1.21 \%)$ & $0(0.0 \%)$ & $1(1.62 \%)$ & NS \\
\hline CRT-D & $4(4.82 \%)$ & $0(0.0 \%)$ & $4(6.45 \%)$ & NS \\
\hline
\end{tabular}

Data are shown as numbers (percentage). AVG - aortic valve gradient, BAV - bicuspid aortic valve, CRT-D - cardiac resynchronization therapy with defibrillator, $D D D R$ - dual chamber rate adaptive pacemaker, EOA - effective orifice area, ICD - implantable cardioverter, LVEF - left ventricular ejection fraction, PVL - paravalvular leak, TAV - tricuspid aortic valve, TAVI - transcatheter aortic valve implantation, TF - transfemoral approach, TS - trans-subclavian approach, TAo - direct aorta approach, VVIR - single chamber rate adaptive pacemaker.

ogies of BAV. Such a division exists in the literature, e.g., in the publication by Kochman et al. [21].

TAVI procedures in BAV patients may be associated with numerous technical difficulties. The factors which increase the difficulty of TAVI procedures in BAV patients include the number of eccentric calcifications, larger annulus diameter, aortic bulb and ascending aorta, longer cusps, lack of consensus concerning the use of annular and aortic valve measurements in valve selection [2-6, 10, 22]. It is uncertain whether the same valve selection methods should be used for bicuspid and tricuspid morphology.
In our study population, BAV occurred in $24.7 \%$ of patients. Its prevalence is, therefore, much higher than that reported by the European registries, where it ranges from $2.7 \%$ to $6.7 \%$, but lower than in the Chinese population, where its prevalence in patients who have undergone TAVI is $37.1 \%[2,11,23,24]$. The prevalence of BAV in our study is similar to the observations of Roberts et al. [7]. Their observations are based on surgical aortic valve replacement in patients with aortic stenosis and on the analysis of excised aortic valves. The analysis does not include patients with rheumatic aortic valve stenosis. 
Table III. Composite endpoints

\begin{tabular}{|c|c|c|c|}
\hline Variable & $\operatorname{BAV}(n=21)$ & $\operatorname{TAV}(n=62)$ & $P$-value \\
\hline \multicolumn{4}{|l|}{ Device success: } \\
\hline Absence of procedural mortality & $21(100 \%)$ & $61(98.38 \%)$ & NS \\
\hline $\begin{array}{l}\text { Correct positioning of a single prosthetic aortic valve into the proper ana- } \\
\text { tomical location }\end{array}$ & 19 (90.47\%) & $60(96.77 \%)$ & NS \\
\hline Intended performance of the prosthetic aortic valve & $18(85.71 \%)$ & $58(93.54 \%)$ & NS \\
\hline Composite endpoints (expressed as the number of patients) & $16(76.19 \%)$ & $55(88.71 \%)$ & NS \\
\hline \multicolumn{4}{|l|}{ Early safety (at 30 days): } \\
\hline All-cause mortality & $1(4.76 \%)$ & $6(9.68 \%)$ & NS \\
\hline All stroke (disabling and non-disabling) & $0(0.0 \%)$ & $1(1.62 \%)$ & NS \\
\hline Life-threatening bleeding & $3(14.29 \%)$ & $5(8.06 \%)$ & NS \\
\hline Acute kidney injury - Stage 2 or 3 (including renal replacement therapy) & $0(0.0 \%)$ & $2(3.23 \%)$ & NS \\
\hline Coronary artery obstruction requiring intervention & $0(0.0 \%)$ & $0(0.0 \%)$ & NS \\
\hline Major vascular complication & $3(14.29 \%)$ & $4(6.45 \%)$ & NS \\
\hline Valve-related dysfunction requiring repeat procedure & $0(0.0 \%)$ & $0(0,0 \%)$ & NS \\
\hline Composite endpoints (expressed as the number of patients) & $5(23.81 \%)$ & $11(17.74 \%)$ & NS \\
\hline \multicolumn{4}{|l|}{ Clinical efficacy (1-year evaluation): } \\
\hline All-cause mortality (1-year evaluation) & $6(28.57 \%)$ & $11(17.74 \%)$ & NS \\
\hline Stroke (disabling and non-disabling) & $0(0.0 \%)$ & $2(3.23 \%)$ & NS \\
\hline $\begin{array}{l}\text { Requiring hospitalizations for valve-related symptoms or worsening conges- } \\
\text { tive heart failure }\end{array}$ & $4(19.05 \%)$ & $9(14.52 \%)$ & NS \\
\hline NYHA class III or IV & $3(14.29 \%)$ & $6(9.67 \%)$ & NS \\
\hline Valve-related dysfunction & $3(14.29 \%)$ & $9(14.52 \%)$ & NS \\
\hline Composite endpoints (expressed as the number of patients) & $10(47.62 \%)$ & $28(45.16 \%)$ & NS \\
\hline
\end{tabular}

Data are shown as numbers (percentage). BAV - bicuspid aortic valve, EOA - effective orifice area, NYHA - New York Heart Association, TAV - tricuspid aortic valve.

In the study of Sievers and Schmidtke [14], based on reports from 1,206 surgical aortic valve replacement, BAV was diagnosed in 33.9\% (409) of patients with aortic defects: stenosis, regurgitation, and combined aortic defect. Perlman et al. diagnosed BAV based on MSCT examination and found it in $12 \%$ of patients who underwent TAVI [20]. In most cases, Jilaihawi et al. diagnosed BAV on MSCT scans and confirmed a significant discrepancy in the prevalence of BAV [19]. On average, BAV was found

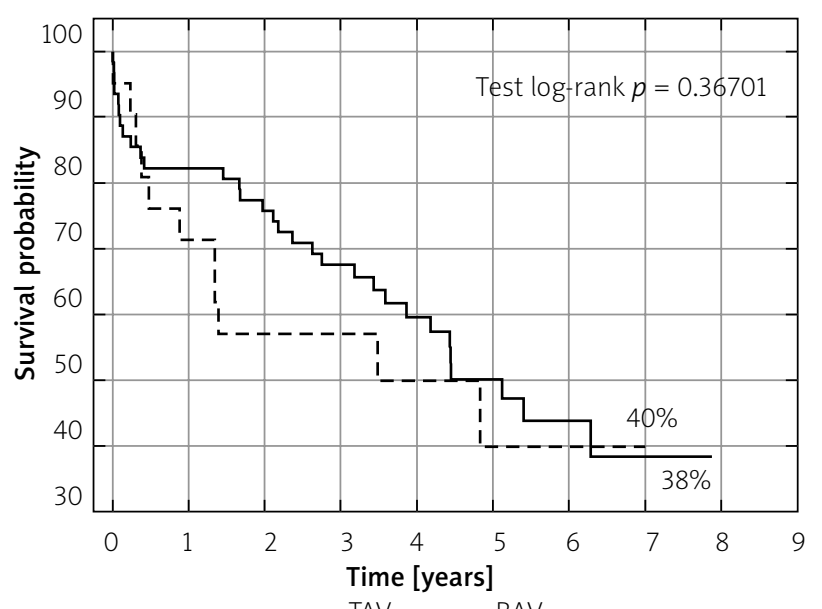

Figure 3. Kaplan-Meier's survival probability BAV - bicuspid aortic valve, TAV - tricuspid aortic valve. in $2.5 \%$ of patients; however, in the Italian center participating in the study, it was $0.32 \%$, and in the Chinese center it was up to $66.7 \%$ [19].

The percentage of patients with BAV will increase with the decrease in the age of patients eligible for TAVI. Roberts et al. found that in the group of patients aged 61-70, the rate of those with BAV is $59.8 \%$ [7]. The high percentage of BAV patients in our study may indicate underestimating the percentage of BAV patients in the registries and observational studies. On the other hand, it means a frequent treatment of BAV patients without awareness of the presence of this malformation. The high percentage of BAV patients in our study is also due to its diagnosis with MSCT scans. The superiority of MSCT examination to echocardiography was proven by Tanaka et al., who stated that the use of MSCT examination has $94.1 \%$ sensitivity and $100 \%$ specificity regarding the diagnosis of BAV [25]. The analysis based on echocardiography showed that $20 \%$ of BAV patients are not identified. In our study, we were not able to define the valve type based on MSCT scans in $12(7.4 \%)$ patients (Figure 1). Kim et al. found that in $16 / 217$ (7.4\%) BAV patients, the BAV phenotype could not be defined [26]. The groups of patients included in our study were well balanced. In our study, comparable results were obtained among BAV and TAV patients, assessed on the basis of VARC criteria. Good results were also obtained in terms of annual survival (Figure 3 ). 
Our 30-day and 1-year mortality results are comparable to other studies (Table IV) [24-33]. The differences regarding mortality and other complications such as life-threatening bleeding could be explained by the qualification of patients in our study with a higher risk of surgical treatment and numerous comorbidities, and the use of first-generation valves in most cases. The high 1-year mortality rate also reflects the complex profile of patients qualified for TAVI in Polish centers in the examined years, related to financial constraints and access to treatment.

There were no differences in the frequency of permanent pacemaker implantation or the prevalence of moderate/severe paravalvular leak. Furthermore, the two study groups did not differ in terms of the mean transvalvular gradient in echocardiographic and hemodynamic measurements immediately after the procedure. A relatively high percentage of permanent pacemaker implantation was found in our patients. This is probably associated with the rare use of fully repositionable Evolut $R$ valves in the study.

BAV patients have not been eligible for randomized trials so far [34-37]. Other non-randomized, observational studies concerning the comparison of TAVI procedures in BAV and TAV patients yielded ambiguous results. Bauer et al. found a higher prevalence of aortic regurgitation in BAV patients [23]. Costopoulos et al. discovered that TAVI in BAV patients is characterized by higher early mortality and lower procedure efficacy [11]. On the other hand, de Biase et al. demonstrated that in the group of BAV patients, TAVI-in-TAVI procedures should be performed more frequently, indicating lower efficacy of TAVI procedures in
BAV patients [30]. Hayashida et al. stated that TAVI procedures in BAV patients gave the same results as in TAV patients [2]. Meanwhile, Yoon et al. reported comparable results, but with newer valve generation only [22]. The use of older generation valves was associated with lower efficacy of the procedure, mainly due to more frequent conversion to surgery, the need to implant a second valve, and more frequent PVL; different valves, ways of diagnosing BAV, and methods of valve selection were applied. Two recent observational studies on TAVI procedures in BAV and TAV patients employed propensity score matching. Makkar et al. did not find differences between BAV and TAV patients in terms of 30-day and 1-year mortality. They found a significantly higher risk of stroke during the 30-day observation, a higher risk of annulus rupture, conversion to surgery, permanent pacemaker implantation, and a higher incidence of a severe paravalvular leak in BAV patients after TAVI. Third-generation balloon-expandable valves were used in this study [32]. Forrester et al. did not find differences between BAV and TAV patients in terms of total mortality, stroke, or valve hemodynamics. Evolut R and Evolut Pro self-expanding valves were used in this study [33]. The authors demonstrated a longer procedure time and a higher rate of reoperations on the aortic valve in BAV patients [33]. Following this study, Medtronic received a CE mark to indicate the Evolut $R$ valve in intermediate, high, and extremely high-risk BAV patients. The population in our study is slightly different from those in the registry in terms of BAV prevalence, less frequent history of myocardial infarction, coronary intervention, and $C A B G$ in BAV patients.

Table IV. 30-day and 1-year mortality across the studies

\begin{tabular}{|c|c|c|c|c|}
\hline \multirow[t]{2}{*}{ Study } & \multicolumn{2}{|c|}{ 30-day mortality } & \multicolumn{2}{|c|}{ 1-year mortality } \\
\hline & BAV & TAV & BAV & TAV \\
\hline Himbert et al. 2012 [24] & $6.6 \%$ & & & \\
\hline Hayashida et al. 2013 [2] & $4.8 \%$ & $8.2 \%$ & & \\
\hline Mylotte et al. 2014 [3] & $5.0 \%$ & & $17.5 \%$ & \\
\hline Kochman et al. 2014 [27] & $4.0 \%$ & $7.0 \%$ & $18 \%$ & $17 \%$ \\
\hline Bauer et al. 2014 [23] & $11.0 \%$ & $11.0 \%$ & $13.0 \%$ & $20.0 \%$ \\
\hline Costopoulos et al. 2014 [11] & $14.0 \%$ & $4.0 \%$ & $32.0 \%$ & $14.0 \%$ \\
\hline Yousef et al. 2015 [28] & $8.3 \%$ & & $16.9 \%$ & \\
\hline Perlman et al. 2016 [20] & $3.9 \%$ & & & \\
\hline Jilaihawi et al. 2016 [19] & $3.8 \%$ & & & \\
\hline Yoon et al. 2017 [22] & $3.7 \%$ & $3.3 \%$ & $\begin{array}{c}11.4 \% \\
\text { Early-generation devices: } \\
14.5 \% \\
\text { New-generation devices: } \\
4.5 \%\end{array}$ & $\begin{array}{r}11.2 \% \\
13.7 \% \\
7.4 \% \\
\end{array}$ \\
\hline Sannino et al. 2017 [29] & $3.4 \%$ & $3.1 \%$ & $8.5 \%$ & $10.5 \%$ \\
\hline de Biase et al. 2018 [30] & $5.0 \%$ & $3.0 \%$ & & \\
\hline Tchetche/de Biase et al. 2019 [31] & $0.0 \%$ & $3.4 \%$ & & \\
\hline Makkar et al. 2019 [32] & $2.6 \%$ & $2.5 \%$ & $10.5 \%$ & $12.0 \%$ \\
\hline Forrest et al. 2020 [33] & $2.6 \%$ & $1.7 \%$ & $10.4 \%$ & $12.1 \%$ \\
\hline
\end{tabular}

BAV-bicuspid aortic valve, TAV - tricuspid aortic valve. 
In our view, valve selection plays a decisive role in the treatment outcomes of BAV patients. The rules relating to the methods of valve selection have not been established yet; however, several methods have been proposed. Annular sizing is the most common one, but other valve selection methods are also possible, such as balloon sizing, 1- or even 2-size downsizing, sizing based on inter-commissural distance, as well as increasingly popular supra-annular sizing $[26,31,38]$. Doubts arise as to the fact that the bicuspid aortic valve perimeter at the margin height is approximately $2 / 3$ of the annulus circumference and that three types of aortic valve implantation landing zones (tube, flare, and taper) emerge from measurements of the annulus diameter and inter-commissural distance $[25,31]$. In our study, the valve selection was based on the annulus perimeter measurements taken during MSCT examination. Firstly, this conviction stems from the fact that the authors obtained good results in reducing PVL using valve selection based on annulus perimeter measurements obtained from MSCT scans (in comparison to echocardiography) [39]. Secondly, it also results from the fact that the CoreValves and Evolut $R$ valves were designed to be placed on the annulus, not to be anchored at the height of the cusps or the inter-commissural distance. In addition, the CoreValves and Evolut $R$ valves are of a tapered shape in cross-section at the base. Valve implantation based on the annular sizing method results in selecting larger valves, which yields a larger effective orifice area and a lower gradient. A higher gradient after valve implantation, often due to valve deformation with $\mathrm{BAV}$, can be reduced by post-dilatation, thus changing the valve's shape to a more circular one at the level of the native margins of the valves, which improves the mobility of the cusps and prolongs the valve's durability. The supra-annular sizing method was applied by the authors in 4 patients excluded from the high-risk cardiac surgery treatment due to very large aortic valve annuli (> $30 \mathrm{~mm}$ ) and the proctor's suggestion. Those patients' data were deleted from the analysis so that the study group could be treated in the same way.

Only one type of valve was used in the study, initially because of the conviction that the balloon-expandable valves should not be used in bicuspid valves due to the more frequent elliptical shape of the annulus, which could cause the valve deformation and worsen its performance. It could impact the durability of the prosthetic valves. Philip et al. reported that the annulus in BAV valves had mostly a round shape [40]. This is confirmed by the measurements taken in our study. The annuli did not differ significantly in terms of minimal and maximal diameter and the degree of ellipticity. There are some reports regarding the beneficial effects of BAV patients' treatment using balloon-expandable valves $[22,32]$. There is a different selection method for each valve type - based on the annulus diameter and radial force of a given valve - each of them (self-expanding, balloon-expandable, and mechan- ically expandable valves) has a different optimal degree of oversizing, specified by the manufacturer). Comparing TAVI procedures in BAV and TAV patients, if different valve types are applied, it may lead to incorrect conclusions. In the future, it is advisable to compare the treatment results of BAV patients among patients in whom different valve selection methods have been applied in order to assess which one is optimal for BAV patients.

Limitations of the study: The study has many limitations due to its retrospective nature and the fact that it is a single-center study with a small number of patients. The small number of patients could have contributed to the lack of clinical and anatomical differences between the studied groups. Another limitation is the lack of analysis of MSCT scans by a dedicated, independent core-lab in terms of valve morphology, mainly because in our study, the BAV percentage was higher than in other studies. In the case of $25 \%$ of our patients, BAV was described as functional, which is usually associated with less calcification at the site of leaflet commissures. This could have impacted the results. Although three experienced interventional cardiologists independently assessed paravalvular leaks after TAVI, the fact that this parameter was not evaluated in dedicated core-labs should be considered another limitation of this study. It is now believed heavily calcified BAV and/or with long heavily calcified raphae are prone to worse PVL grade and clinical outcome. However, the aim of the study was not to analyze the calcification volume and its impact on PVL. Furthermore, the use of first-generation valves in most patients could be viewed as a limitation as well.

\section{Conclusions}

In the short- and medium-term, the treatment of patients with severe aortic stenosis and the bicuspid aortic valve is as effective as that with the tricuspid aortic valve using self-expanding TAVI valves when the valve size selection is based on annular sizing using MSCT scans. However, these results require confirmation in studies on a larger population and studies comparing different prosthesis selection methods in BAV patients.

\section{Conflict of interest}

The authors declare no conflict of interest.

\section{References}

1. Kochman J, Rymuza B, Huczek Z. Transcatheter aortic valve replacement in bicuspid aortic valve disease. Curr Opin in Cardiol 2015; 30: 594-602.

2. Hayashida K, Bouvier E, Lefèvre T, et al. Transcatheter aortic valve implantation for patients with severe bicuspid aortic valve stenosis. Circ Cardiovasc Interv 2013; 6: 284-91.

3. Mylotte D, Lefevre T, Søndergaard L, et al. Transcatheter aortic valve replacement in bicuspid aortic valve disease. J Am Coll Cardiol 2014; 64: 2330-9. 
4. O'Sullivan CJ, Windecker S. Implications of bicuspid aortic valves for transcatheter aortic valve implantation. Circ Cardiovasc Interv 2013; 6: 204-6.

5. Spatuzza P, Ruparelia N, Latib A. Bicuspid aortic valves and TAVI: is it still an exclusion criterion? State of the art and open issues. Interv Cardiol 2015; 7: 381-8.

6. Roman MJ, Pugh NL, Devereux RB, et al. Aortic dilatation associated with bicuspid aortic valve: relation to sex, hemodynamics, and valve morphology (the National Heart Lung and Blood Institute-Sponsored National Registry of Genetically Triggered Thoracic Aortic Aneurysms and Cardiovascular Conditions). Am J Cardiol 2017; 120: 1171-5.

7. Roberts WC, Ko JM. Frequency by decades of unicuspid, bicuspid, and tricuspid aortic valves in adults having isolated aortic valve replacement for aortic stenosis, with or without associated aortic regurgitation. Circulation 2005; 111: 920-5.

8. Hamm CW, Mollmann H, Holzhey D, et al. The German Aortic Valve Registry (GARY): in-hospital outcome. Eur Heart J 2014; 35: 1588-98.

9. Gilard M, Eltchaninoff H, Donzeau-Gouge P, et al. Late outcomes of transcatheter aortic valve replacement in high-risk patients. J Am Coll Cardiol 2016; 68: 1637-47.

10. Baumgartner H, Falk V, Bax J, et al. 2017 ESC/EACTS Guidelines for the management of valvular heart disease. Eur Heart J 2017; 38: 2739-91.

11. Costopoulos C, Latib A, Maisano F, et al. Comparison of results of transcatheter aortic valve implantation in patients with severely stenotic bicuspid versus tricuspid or nonbicuspid valves. Am J Cardiol 2014; 113: 1390-3.

12. Reddy G, Wang Z, Nishimura RA, et al. Transcatheter aortic valve replacement for stenotic bicuspid aortic valves: systematic review and meta analyses of observational studies. Catheter Cardiovasc Interv 2018; 91: 975-83.

13. Wilczek K, Chodór P, Walas R. "Vale-in-valve" - first Polish experience in transcatheter treatment of patient with high-risk of redo surgery for degenerative disease of aortic bioprosthesis, using tranaxillary access. Kardiol Pol 2010; 68: 980-4.

14. Sievers HH, Schmidtke C. A classification system for the bicuspid aortic valve from 304 surgical specimens. J Thorac Cardiovasc Surg 2007; 133: 1226-33.

15. Wilczek K, Chodór P, Laborde JC, et al. Percutaneous transfemoral aortic CoreValve(R) implantations in high risk patients: another Polish good experience. Kardiol Pol 2009; 67: 1162-5.

16. Chodór P, Wilczek K, Przybylski R, et al. Immediate and 6-month outcomes of transapical and transfemoral Edwards-Sapien prosthesis implantation in patients with aortic stenosis. Kardiol Pol 2010; 68: 1124-31.

17. Sellers RD, Levy MJ, Amplatz K, et al. Left retrograde cardioangiography in acquired cardiac disease. Am J Cardiol 1964; 14 437-47.

18. Kappetein AP, Head SJ, Généreux P, et al. Updated standardized endpoint definitions for transcatheter aortic valve implantation: the Valve Academic Research Consortium-2 consensus document. J Thorac Cardiovasc Surg 2013; 145: 6-23.

19. Jilaihawi $H$, Chen $M$, Webb J, et al. A bicuspid aortic valve imaging classification for the TAVR era. JACC Cardiovasc Imaging 2016; 9: 1145-58.

20. Perlman GY, Blanke P, Dvir D, et al. Bicuspid aortic valve stenosis. JACC Cardiovasc Interv 2016; 9: 817-24.

21. Kochman J, Zbroński K, Kołtowski Ł, et al. Transcatheter aortic valve implantation in patients with bicuspid aortic valve steno- sis utilizing the next-generation fully retrievable and repositionable valve system: mid-term results from a prospective multicentre registry. Clin Res Cardiol 2020; 109: 570-80.

22. Yoon SH, Bleiziffer S, De Backer O, et al. Outcomes in transcatheter aortic valve replacement for bicuspid versus tricuspid aortic valve stenosis. J Am Coll Cardiol 2017; 69: 2579-89.

23. Bauer T, Linke A, Sievert $H$, et al. Comparison of the effectiveness of transcatheter aortic valve implantation in patients with stenotic bicuspid versus tricuspid aortic valves (from the German TAVI Registry). Am J Cardiol 2014; 113: 518-21.

24. Himbert D, Pontnau F, Messika-Zeitoun D, et al. Feasibility and outcomes of transcatheter aortic valve implantation in high-risk patients with stenotic bicuspid aortic valves. Am J Cardiol 2012; 110: 877-83.

25. Tanaka R, Yoshioka K, Niinuma H, et al. Diagnostic value of cardiac CT in the evaluation of bicuspid aortic stenosis: comparison with echocardiography and operative findings. AJR Am J Roentgenol 2010; 195: 895-9.

26. Kim WK, Renker M, Rolf A, et al. Annular versus supra-annular sizing for TAVI in bicuspid aortic valve stenosis. Eurolntervention 2019; 15: e231-8.

27. Kochman J, Huczek Z, Scisło P, et al. Comparison of one- and 12-month outcomes of transcatheter aortic valve replacement in patients with severely stenotic bicuspid versus tricuspid aortic valves (results from a multicenter registry). Am J Cardiol 2014; 114: 757-62

28. Yousef A, Simard T, Webb J, et al. Transcatheter aortic valve implantation in patients with bicuspid aortic valve: a patient level multi-center analysis. Int J Cardiol 2015; 189: 282-8.

29. Sannino A, Cedars A, Stoler RC, et al. Comparison of efficacy and safety of transcatheter aortic valve implantation in patients with bicuspid versus tricuspid aortic valves. Am J Cardiol 2017; 120: 1601-6.

30. De Biase C, Mastrokostopoulos A, Philippart R, et al. Aortic valve anatomy and outcomes after transcatheter aortic valve implantation in bicuspid aortic valves. Int J Cardiol 2018; 266: 56-60.

31. Tchetche D, de Biase C, van Gils L, et al. The BAVARD Multicenter Registry: a European picture of contemporary multidetector computed tomography sizing for bicuspid valves. Circ Cardiovasc Interv 2019; 12: e007107.

32. Makkar RR, Yoon SH, Leon MB, et al. Association between transcatheter aortic valve replacement for bicuspid vs tricuspid aortic stenosis and mortality or stroke. JAMA 2019; 321: 2193-202.

33. Forrest JK, Kaple RK, Ramlawi B, et al. Transcatheter aortic valve replacement in bicuspid versus tricuspid aortic valves from the STS/ACC TVT Registry. JACC Cardiovasc Interv 2020; 13: 1749-59.

34. Rogers T, Thourani VH, Waksman R. Transcatheter aortic valve replacement in intermediate- and low-risk patients. J Am Heart Assoc 2018; 7: e007147

35. Leon MB, Smith CR, Mack M, et al. Transcatheter aortic-valve implantation for aortic stenosis in patients who cannot undergo surgery. N Engl J Med 2010; 363: 1597-607.

36. Leon MB, Smith CR, Mack MJ, et al. Transcatheter or surgical aortic-valve replacement in intermediate-risk patients. $\mathrm{N}$ Engl J Med 2016; 374: 1609-20.

37. Thyregod HGH, Steinbrüchel DA, Ihlemann N, et al. Transcatheter versus surgical aortic valve replacement in patients with severe aortic valve stenosis. J Am Coll Cardiol 2015; 65: 2184-94.

38. Liu X, He Y, Zhu Q, et al. Supra-annular structure assessment for self-expanding transcatheter heart valve size selection in 
patients with bicuspid aortic valve. Catheter Cardiovasc Interv 2018; 91: 986-94.

39. Chodór P, Wilczek K, Przybylski R, et al. Impact of CoreValve size selection based on multi-slice computed tomography on paravalvular leak after transcatheter aortic valve implantation. Cardiol J 2017; 24: 467-76.

40. Philip F, Faza NN, Schoenhagen P, et al. Aortic annulus and root characteristics in severe aortic stenosis due to bicuspid aortic valve and tricuspid aortic valves: implications for transcatheter aortic valve therapies. Catheter Cardiovasc Interv 2015; 86: E88-98. 